\title{
Modifying the ISEW and taking into account energy
}

\author{
E. B. P. Tiezzi ${ }^{1}$, M. Bravi ${ }^{2}$ \& F. M. Pulselli ${ }^{2}$ \\ ${ }^{I}$ Department of Mathematical Sciences "Roberto Magari", \\ University of Siena, Siena, Italy \\ ${ }^{2}$ Department of Chemistry, University of Siena, Siena, Italy
}

\begin{abstract}
The Index of Sustainable Economic Welfare (ISEW) introduced by H. Daly and J. Cobb in 1989, can be used to have comprehensive knowledge of the characteristics of the economic system: in fact, items included in the ISEW allow this accounting method to make a more recognisable picture of reality. This case study presents an analysis of the ISEW calculated for the Province of Siena, Central Italy. The main aim is to quantify significant benefits when policies designed to reduce the use of fossil fuels are applied to the local economy. Discussion focuses on the role of ISEW as an indicator able to evaluate the usefulness of a given energy project/policy.
\end{abstract}

Keywords: sustainability assessment, ISEW, energy policy, local level.

\section{Introduction}

The necessity to engage with orthodox economists in a discussion about wealth and welfare and some senseless interpretation on the growth rate of GDP is the basis for developing more inclusive measure of economic welfare. An indicator such as the Index of Sustainable Economic Welfare (ISEW) introduced by Daly and Cobb (1989) is a result of this necessity. In fact, ISEW still has a strong correlation with GDP and economic basic rules, but at the same time it changes the point of view from growth to sustainability. Starting with consumption, the authors proposed some adjustments to allow for inequality of income distribution, environmental problems (such as pollution costs, long term environmental damage, depletion of non-renewable resources) and social issues (such as commuting costs, urbanization costs, public expenditure for health and 
education). Computations for different nations have shown that the ISEW increases together with GDP up to a point, beyond which it stagnates or even decreases, due to the environmental and social pressures of economic growth [1-4].

This paper shows the results from the calculation of the ISEW 2003 of Province of Siena (Italy) in 2003. The ISEW has been calculated at the local level, in order to give local authorities further information for taking proper political decisions under a sustainable viewpoint. The local (regional or provincial) level often represents the optimal dimension for implementing policies, especially in certain fields. This is mainly due to a major attention paid by local institutions for peculiar problems and to the administrative decentralization.

In January 2008 the European Commission published the Directive on the promotion of energy from renewable sources which commits the EU27 to increasing its share of renewable energy production to $20 \%$ by 2020 . These targets present challenges for policymakers in allocation scarce resources to promote renewable energy source technology and energy efficiency uptake, particularly when considering the range and complexity of solutions available.

The aim of this work is to show the ISEW sensitivity in evaluating policies of energy efficiency and renewable energy supply for a local territorial system. Furthermore public authorities must have information about natural capital, economy and social aspect, to understand the consequences of their choices inside and outside their local territorial system. We show that ISEW can be used to do this.

\section{Methods}

The ISEW calculation is divided into 23 items. Item A is the reference year; this analysis was presented for 2003. Items B and D are row and adjusted consumption, respectively. The latter is calculated on the basis of the Gini index of income distribution (item $\mathrm{C}$ ). Items $\mathrm{E}, \mathrm{F}, \mathrm{G}$ and $\mathrm{H}$ are positive values, corresponding to services that contribute to welfare, though not considered in conventional national accounting. Items I to $\mathrm{Q}$ are negative because they correct the overestimation of economic welfare with respect to the level of private consumption. Items $\mathrm{R}, \mathrm{S}, \mathrm{T}$ and $\mathrm{U}$ are usually negative since they are estimates of the consumption of structural fractions of Natural Capital without any real counterpart in terms of welfare.

The following paragraphs are devoted to the description of the whole procedure.

Local data sources have been used, when possible, reducing the need of scaling down the national data to the local level, and avoiding arbitrary estimates. All monetary values were expressed in Euro in 2003.

The whole calculation procedure is available at the Environmental Office of the Province of Siena. 
Private consumption - $B,-D$; index of income distribution - $C$

Private Consumption (B) is the primary variable directly affecting economic welfare because large household expenditures in goods and services are considered to be an indicator of a wealthy economy and a healthy society.

Data for this variable were obtained from the statistical reports for the Province of Siena provided by the National Statistic Bureau (ISTAT) [5].

Private Consumption is adjusted according to an index of income distribution the Gini's index $(\mathrm{C})$. The range of variation of this index is between 0 and 1 (where 0 means perfect income distribution and 1 means maximum inequality). The value of Gini index was computed from data in Cannari and D'Alessio [7]. The adjusted private consumption (D) is the basis to which all other positive and negative items are added or subtracted.

Services and domestic labour - $E$

Domestic labour (E) contributes directly to economic welfare, even if it does not imply money exchange. The income per hour attributed to domestic labour (data of market wages was obtained by ISTAT) [8] was multiplied by the hours spent at home by people over 14 years of age, as suggested by Guenno and Tiezzi [9].

It was assumed that a housewife spends $8 \mathrm{~h} /$ day in housework, an unemployed person $4 \mathrm{~h} /$ day and a student $2 \mathrm{~h} /$ day.

Services from durable goods - F; - I: Expenditure on durable goods

Expenditure on durable goods such as cars and household appliances does not reflect the real welfare of consumers, because it is necessary to consider the utilization period of these goods. Hence, services (item F) from these goods are considered as benefits, while the initial capital (item I) is a cost that must be subtracted from private consumption. The services from a variety of goods (houses, household appliances, personal computers, mobile phones and cars) were calculated on the basis of data from the Bank of Italy [10] and Pulselli et al. [11].

Expenditure on durable goods (televisions, personal computers, cars) does not represent the welfare derived from their use. These goods provides utility (and thus welfare) along their life time. This figure must be subtracted from consumption. All data are provided by ISTAT [5].

Public expense: Services from public infrastructure - G; Public health care and education cost - $H$

Daly and Cobb [6] consider that public costs should not be a component of economic welfare because they are part of defensive costs, with the exception of services from public infrastructure (item $G$ ) and health and education costs (item $\mathrm{H})$. Indeed, the growth of administration costs does not contribute to net economic welfare; it keeps economic welfare from declining, maintaining a healthy environment and conditions which contribute to trade and commerce.

Item $G$ is the sum of the value of services of the road system (equal to the cost of their maintenance) and the value of current public expenses in urban development. All data are collected from personal communications from Agency of Land development and Viability of the Province of Siena. 
Public health care and education costs are included in GDP because they are part of public expenses. Daly and Cobb [6] consider that $50 \%$ of this expenditure (both health care and education) is a defensive cost and should not be added to the index calculations, while Guenno and Tiezzi [9] believe that only 50\% of health care costs are defensive. Hence, $100 \%$ of the public education costs and $50 \%$ of health care costs are added. Data are collected from ISTAT and from Ministry of Education and University $[12,13]$.

Private defensive expenditures for education and health care - $J$

Private defensive expenditures for education and health care are included in consumption but only a fraction of them is non-defensive and correlated to welfare. The defensive fraction (the $50 \%$ of both) must be subtracted from private consumption. Information is collected from ISTAT [5].

Local advertising cost $-K$

Advertising costs are mostly aimed at stimulating or maintaining the demand for a certain product, without a real counterpart in terms of collective welfare. Per capita advertising costs in Italy are equal to about $190 \$$.

Cost of commuting - $L$

Like Daly and Cobb [6] and Guenno and Tiezzi [9], we consider that the $30 \%$ of the costs related to private cars and public transport, together with the $30 \%$ of public and private maintenance cost, is not related to welfare because it depends on urbanization, overcrowding and traffic. Data comes from Automobile Club Italia (ACI) [14] and they are directly related to commuting costs, according to the following equation:

$$
L=0.3 \alpha+0.3 \beta+0.3 \gamma
$$

where: Item $L$ is the cost of commuting; $\alpha$ is the total value of cars in the area; $\beta$ is the expenditure for public transport tickets; $\gamma$ is the cost for public and private vehicle maintenance; 0.3 is the portion of services related to commuting (e.g. the time we are forced to spend because of traffic).

Urbanization cost - $M$ not computed due to the lack of data.

Cost of car accidents $N$

This cost is a negative item because it corresponds to a decrease in economic welfare. The cost of car accidents was calculated from total payments of insurance premiums. We used the method proposed by Guenno and Tiezzi [9]. ANIA-Associazione Nazionale Imprese Assicuratrici [15] provided data.

Pollution: Cost of water pollution O; Cost of air pollution P; Cost of noise pollution $Q$

Pollution is a cost for society, that must be subtracted from private consumption because it does not contribute to welfare. We considered the three main form of pollution:

Water pollution: as in the case of Italy [9], we used total costs for water purification, obtained from a standard purification plant. The cost is referred to the equivalent inhabitants (E.I.) of the area, as the pollution measure. The 
number of E.I. of the Province of Siena was obtained by summing resident population, E.I. of industrial sector, and E.I. of agriculture and zootechnic sector;

Air pollution: Like Guenno and Tiezzi [3], we considered types of emissions and their cost per ton of emission abatement $\left(\mathrm{SO}_{\mathrm{x}}: 2324 \mathrm{Euro} / \mathrm{t} ; \mathrm{NO}_{\mathrm{x}}: 904 \mathrm{Euro} / \mathrm{t}\right.$; TSP (total suspended particles): 130 Euro/t; $\mathrm{CO}_{2}: 10$ Euro/t). Specific cost is multiplied by the quantity of emissions calculated following the 1996 Guidelines of Greenhouse Gas National Inventories [16];

Noise pollution: in calculating this item, we consider noise pollution due to vehicular traffic. The environmental agency of Tuscany Region provided an estimation of the value of noise pollution attributed to cars.

\section{Loss of wetlands $R$}

Wetlands host some of the most biologically productive habitats in the world. Their value has not been included in economic accounting because they are considered part of natural capital and difficult to monetize. The ISEW addresses this issue by estimating the value of services lost when wetlands are converted into other uses.

\section{Loss of agricultural land $S$}

Agricultural land productivity is fundamental for every society and has been progressively reducing for a long time due to two destructive processes. Urban expansion and bad land management (allowing erosion, intensive agricultural practices, decomposition of organic material) have led to the depletion of agricultural land and a reduction in yields.

The result represents the definitive loss of available bio-productive land due to the change in use. The monetary value of agricultural land was obtained from the Provincial Office of Agriculture (personal communication).

\section{Depletion of non-renewable resources $T$}

According to El Serafy [17], a portion of the economic profit of resource extraction should be reinvested to preserve the capacity of the economic system to produce a durable income for future generations.

Daly and Cobb [6] assumed that the value of total net returns from the sale of non-renewable resources should be counted as depreciation.

\section{Long-term environmental damage $U$}

A fundamental element that contributes to well-being in the long run is the conservation and protection of natural ecosystems which represent a source of biological production. Modern economic infrastructure, with its industrial and commercial practices tends to ignore physical rules and the inability of ecosystems to support these practices indefinitely. The production of toxic wastes, carbon-dioxide, nuclear wastes and chlorofluorocarbons, with their durable deleterious effects, is a real cost which will fall on future generations.

Long-term environmental damage is directly proportional to the consumption of fossil fuels and energy. Hence, petrol, diesel fuel, fuel oil, methane and electricity consumption time series were considered and converted in oil barrel. Daly and Cobb [6] used a tax of $0.50 \$$ in the 1972 per oil barrel (equal to 
1.96 Euro in the 2003), in order to determine the amount of money that must be accumulated year after year and maintained for compensating future generations.

Net capital growth $V$

In order to sustain long-term economic welfare, there should be an increasing or constant supply of capital per worker. ISEW calculates net capital growth (NCG) (item $\mathrm{V}$ ) by adding the stock of new capital $(\Delta \mathrm{K})$ and subtracting the capital requirement $(\mathrm{CR})$. $\mathrm{CR}$ is obtained multiplying the percentage variation in labour force $(\Delta \mathrm{L} / \mathrm{L})$ by the stock of capital of the preceding year $(\mathrm{K}-1)[9]$.

where $\Delta \mathrm{K}=\mathrm{K}-\mathrm{K}_{-1}$ and $\mathrm{CR}=(\Delta \mathrm{L} / \mathrm{L}) \mathrm{K}_{-1}$

$$
\mathrm{NCG}=\Delta \mathrm{K}-\mathrm{CR}
$$

\section{The Index of Sustainable Economic Welfare and local GDP $W$}

The ISEW is obtained by the algebraic sum of all the items, depending on their positive or negative contribution to welfare, as previously indicated. The main features of ISEW, as a measure of sustainable economic welfare, with respect to GDP, are:

- Inclusion of changes in the distribution of income, reflecting the fact that an additional Euro means more to the poor than to the rich;

- Inclusion of household labour;

- Exclusion of expenses to offset social and environmental costs (defensive expenditures)

- Inclusion of long-term environmental damage and depreciation of natural capital (as negative items);

- Inclusion of net production of man-made capital (i.e. net investment).

\section{Discussion and results}

A large number of adjustments to consumption base have been done in order to estimate the ISEW and the differences between positive and negative economic operations. Table 2 shows the value of the items of the Index of Sustainable Economic Welfare for the Province of Siena and provincial GDP. ISEW is only $81 \%$ of GDP that means that the $19 \%$ of wealth produced within the system is not translated into welfare.

In order to test the ISEW as an instrument able to evaluate the benefits of different energy policies, we defined an energy policy target (EPT) and we calculated ISEW variation in relation to the state defined in table 2.

To do this, it is necessary to consider some hypotheses:

1) The EPT is immediately implemented;

2) All the items are maintained constant with the exception of long-term environmental damage $(\mathrm{U})$, depletion of non-renewable resources $(\mathrm{T})$ and cost of air pollution (P), because they are directly affected by a change in energy use.

Table 3 shows the EPT considered, that includes energy saving by implementing conventional technologies like biomass (wood pellet), solar thermal and direct use of geothermal energy to heat dwelling. We established that these technologies can cut fossil fuels and electricity consumption in the 
Table 1: $\quad$ Monetary value of all items of ISEW of the Province of Siena to 2003.

\begin{tabular}{|c|c|c|c|}
\hline $\mathbf{A}$ & & Year & 2003 \\
\hline B & & Personal consumption expenditure & 3.099 .628 .258 \\
\hline $\mathbf{C}$ & & Index of distribution inequality & 0,311 \\
\hline $\mathbf{D}$ & & Weighted personal consumption & 2.364.684.359 \\
\hline $\mathbf{E}$ & + & Services of household labour & 502.524 .000 \\
\hline $\mathbf{F}$ & + & Consumer durables services & 2.276.406.801 \\
\hline G & + & Services from public infrastructure & 5.579 .032 \\
\hline $\mathbf{H}$ & + & Public expenditure on health and education & 344.230 .698 \\
\hline $\mathbf{I}$ & - & Expenditure on consumer durables & 444.376 .283 \\
\hline $\mathbf{J}$ & - & Defensive private expenditure on health and education & 130.277 .249 \\
\hline $\mathbf{k}$ & - & Local advertising expenditure & 43.365 .658 \\
\hline $\mathbf{L}$ & - & Cost of commuting & 176.454 .874 \\
\hline $\mathbf{N}$ & - & Cost of car accidents & 3.932 .103 \\
\hline $\mathbf{O}$ & - & Cost of water pollution & 26.723 .573 \\
\hline $\mathbf{P}$ & - & Cost of air pollution & 21.490 .834 \\
\hline $\mathbf{Q}$ & - & Cost of noise pollution & 21.842 .488 \\
\hline $\mathbf{R}$ & + & Loss of wetlands & 0 \\
\hline $\mathbf{S}$ & - & Loss of agricultural land & 3.953 .190 \\
\hline $\mathbf{T}$ & - & Exhaustible resources depreciation & 205.713 .737 \\
\hline $\mathbf{U}$ & - & Long-term environmental damage & 59.082 .133 \\
\hline $\mathbf{V}$ & + & Net capital growth & 185.852 .953 \\
\hline $\mathbf{W}$ & & ISEW & 4.542 .065 .719 \\
\hline $\mathbf{X}$ & & ISEW per capita & 17.549 \\
\hline $\mathbf{Y}$ & & GDP & 5.602 .180 .545 \\
\hline \multirow[t]{2}{*}{$\mathbf{Z}$} & & GDP per capita & 21.645 \\
\hline & & Population & 258.821 \\
\hline
\end{tabular}

Table 2: $\quad$ Summary of policy 1 .

\begin{tabular}{|l|c|c|c|c|c|}
\hline \multicolumn{1}{|c|}{ Technology } & $\begin{array}{c}\text { Installed } \\
\text { Capacity } \\
(\mathrm{MW})\end{array}$ & $\begin{array}{c}\text { Energy } \\
\text { Production } \\
\text { per year } \\
(\mathrm{GWh})\end{array}$ & $\begin{array}{c}\text { Energy } \\
\text { saving per } \\
\text { year } \\
(\mathrm{kTep})\end{array}$ & $\begin{array}{c}\text { System Cost } \\
\text { (Euro/kW) }\end{array}$ & $\begin{array}{c}\text { Total } \\
\text { investment to } \\
\text { year 2020 }\end{array}$ \\
\hline biomass boiler & 43 & 258 & 22,2 & 300 & $€ 12.900 .000$ \\
\hline solar thermal & 42 & 30 & 2,6 & 700 & $€ 29.400 .000$ \\
\hline use of geothermal source & 70 & 1000 & 86,1 & 2600 & $€ 182.000 .000$ \\
\hline
\end{tabular}

Province of Siena (108,3 kTep and 2,6 kTep, respectively). These renewable energy sources can be used for space heating and/or hot water production in buildings but also in industrial process. 
When a policy is applied, ISEW reflects the effects (see figure 1) that limited the consumption of fossil fuels. Thus, it is possible to test the sensitivity of ISEW to policies of energy saving or promotion of renewable energies. In this case, ISEW variation before and after EPT implementation is only $0.14 \%$, and this means that ISEW methodology, in this form, is not strongly sensitive when it is used to monitor the true efficacy of energy policy at local level. Actually, as shown in figure 2, no variation in ISEW can be seen if compared to GDP.

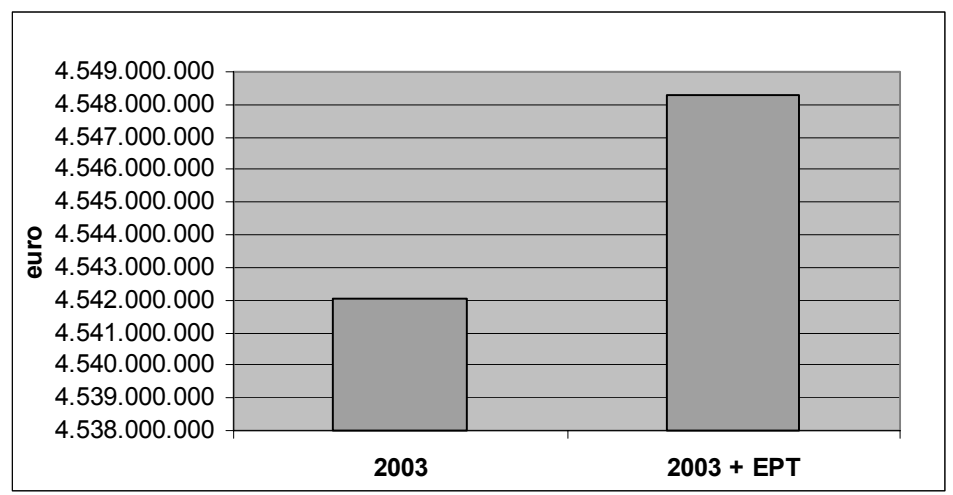

Figure 1: ISEW of the province of Siena.

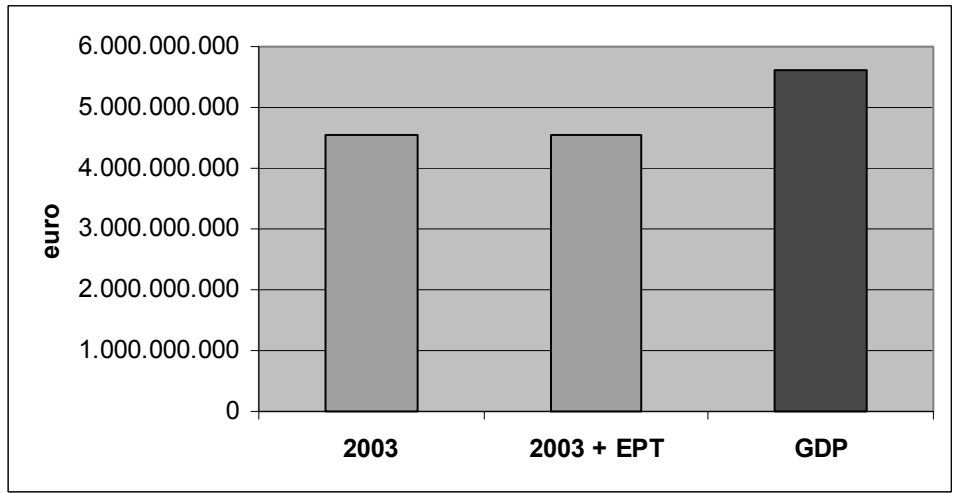

Figure 2: $\quad$ Comparison of GDP and ISEW of the Province of Siena.

In the future we shall focus on the role of ISEW as an indicator able to evaluate the usefulness of a given energy project/policy. To do that, some items like public expenditure on health and education, cost of air pollution and exhaustible resources depreciation, long term environmental damage must be modified. In general, the items that can be affected by a change in energy use represent the $5-15 \%$ of the final value of ISEW. Adequating the calculation method of these items in order to take into account the importance of energy, would be appropriate. 


\section{Conclusions}

In this paper the ISEW of the province of Siena has been presented. The results showed that a relevant gap between the ISEW and local GDP of about 19\% exists, indicating that a portion of wealth is not translated into welfare. Furthermore, we tested the capacity of this indicator to take into account a given energy policy. We considered energy saving by implementing conventional technologies like biomass (wood pellet), solar thermal and direct use of geothermal energy to heat dwelling, that imply a reduction of fossil fuel and energy use. However, no particular change in the final value of the ISEW emerged (the variation was only $0,14 \%$ ). This means that the ISEW in this form is not able to take into account such a policy. We think that this problem can be solved by modifying the calculation of some items like public expenditure on health and education, cost of air pollution, exhaustible resources depreciation and long term environmental damage, making the ISEW a more sensitive sustainability indicator.

\section{References}

[1] Jackson, T., Stymne, S. Sustainable Economic Welfare in Sweden: A Pilot Index 1950-1992. Stockholm Environment Institute, The New Economics Foundation, 46 pp, 1996.

[2] Stockhammer, E., Hochreiter, H., Hobermayr, B., Steiner, K. The index of sustainable economic welfare (ISEW) as an alternative to GDP in measuring economic welfare. The result of the Austrian (revised) ISEW calculation, 1955 - 1992. Ecological Economics, 1997, 21, 19-34.

[3] Guenno, G., Tiezzi, S. The Index of Sustainable Economic Welfare (ISEW) for Italy. Worknote 5.98. Fondazione Enrico Mattei, Milano, Italy, 1998.

[4] Castañeda, B., E. An index of sustainable economic welfare (ISEW) for Chile. Ecological Economics, 1999, 28, 231-244.

[5] ISTAT, 2002. I consumi delle famiglie, 2001. Annuari Famiglia e Società.

[6] Daly, H. E., Cobb, J.B., Un'economia per il bene comune. Il nuovo paradigma economico orientato verso la comunità, l'ambiente e un futuro particolarmente sostenibile. RED edizioni, Como, Italy. 23, 1994.

[7] Cannari L. e D'Alessio G. La distribuzione del reddito e della ricchezza nelle regioni italiane, Temi di discussione Banca d'Italia, n. 482, 2003.

[8] ISTAT, 2005. Le retribuzioni contrattuali annue di competenza nel 2001. Settore lavoro, 15.

[9] Guenno, G., Tiezzi, S. The Index of Sustainable Economic Welfare (ISEW) for Italy. Worknote 5.98. Fondazione Enrico Mattei, Milano, Italy, 1998

[10] Tomat, G.M. Beni durevoli, indici di prezzo e cambiamenti di qualità: un'applicazione ai prezzi delle automobili in Italia (1988-98), 439. Banca d'Italia, Roma, 2002.

[11] Pulselli, F.M., Ciampalini, F., Tiezzi, E., Zappia, C. The Index of Sustainable Economic Welfare (ISEW) for a local authority: a case study in Italy. Ecological Economics, 2006, 60, 271-281. 
[12] MIUR, 2003. La spesa pubblica per l'Istruzione. Elaborazione dell' ufficio di Statistica del Ministero dell'Istruzione, dell'Università e della ricerca su dati ISTAT - Ufficio VI. Roma.

[13] ISTAT, 1983. I conti della protezione sociale - sanità previdenza e assistenza anni 1960-1982. Supplemento al bollettino mensile di statistica, n.28, Roma.

[14] ACI, 2005. Serie storiche sullo sviluppo della motorizzazione e sull'incidentalità stradale in Italia negli anni 1921-2003.

[15] ANIA-Associazione Nazionale fra le Imprese Assicuratrici L'assicurazione italiana 2003/2004; Roma 2004.

[16] IPCC. Climate Change 1995. Impacts, Adaptations and Mitigation of Climate Change: Scientific-Technical Analyses. Cambridge University Press, 879 pp, 1996.

[17] El Serafy, S. The proper calculation of income from depletable natural resources. In: Ahmad, Y.J., Serafy, S.E., Lutz, E., (Eds) Environmental Accounting for Sustainable Development. An UNDP-World Bank Symposium, World Bank, Washington, DC. 10-18, 1988. 